\title{
Open Source and Consumption
}

\author{
Yu-Wei Lin, School of Arts and Media, University of Salford, UK \\ Email: y.lin@salford.ac.uk
}

\begin{abstract}
This article illuminates the common concepts and widely-observed practices concerning open source. Positioning 'open-source' as a common practice and a viable methodology for collaborative participatory co-production in today's knowledge society, the article explains how open-source coproduction participatory methods, now also seen in mundane cultural, food and beverage production and consumption, evolve from the Free/Libre Open Source Software (FLOSS) movement, what motivate people to participate, and how such practices implicate in different sectors in contemporary societies. This article argues that the open-source practices resemble the amateur DIY cultures and can be considered as a lifestyle, elected and subscribed by some. Open source suggests that consumption is no longer simply a passive activity; it could be a personal statement, a liberating, creative and varied experience.
\end{abstract}

Open-sourcing, aligned with 'crowd-sourcing', has emerged to be a viable methodology for collaborative production in today's knowledge society. Largely inspired by the computer hacker culture and the Free/Libre Open Source Software (FLOSS) movement originated in the late 1970s and early 1980s (Moody 2002), open-source refers to the practices of releasing product source code or recipes for the public to scrutinize, study, change, share, distribute and re-distribute the original and/or the modified work. It is believed that open source products (may it be software or hardware) or services, identifiable by open source licenses, feature higher modularity, transparency, openness, compatibility, interoperability, and sustainability than proprietary ones (DiBona et al. 1999).

Though often implicit or invisible, a considerable amount of goods or services modern societies consume everyday are based on FLOSS, co-developed (largely in a voluntary manner but sometimes also with pay) by people from diverse backgrounds in distributed environments. Open source software code, embedded in digital infrastructures or technologies used in aeroplanes, transportation or banking systems, and many social media web services, has enabled faster, more secure and sustainable ICT development. Contemporary society is also witnessing a range of parallel movements such as open standards, open content, open access, open data which are closely associated with free/open source software movement. Notable examples include Wikipedia and OpenStreetMap.

Scholarly research has found that people are motivated to voluntarily contribute to open source projects for different reasons: pragmatic (for work, improving skills, for learning a different programming language, see Raymond 2001), political (freedom of speech, freedom of expression, democracy, see e.g., Coleman 2012), cultural, social (for social and collaborative learning, see Huysman and Lin 2005), religious (for hacker ethics), or personal (just for fun, see Torvalds and Diamond 2011, Lin 2011). For example, through open sourcing, users and consumers can be empowered to have more choices in products, to configure, re-configure, distribute and redistribute, share goods and ideas. The freedoms of doing so are important inasmuch as freedom of 
expression and freedom of information are essential human rights in modern societies. Through sharing, reusing, recycling source code, recipes, and ideas, new values can be added to existing work without reinventing the wheels. To successfully realise an open source project, new roles in FLOSS development that require specialisation in project facilitation, coordination, and management have emerged. Novel business models have also been built around open source projects, mainly provision of customised bespoke software solutions, datasets or items. It is therefore a myth to consider open source a purely altruistic, voluntary activity.

As Lin (2005) argues, as a community of open source practices, the FLOSS social world allows diverse actors to engage in the innovation process and therefore contains more innovation resources than other relatively conventional software development models. The strategic collaboration between the public (i.e., the free software communities) and the private (i.e., information technologies corporations) sectors symbolises a pattern of hybrid innovation that entails complex communications and networks. The development of FLOSS democratises software innovation processes and allows lay people / amateurs to explore their understanding and knowledge of a shared problem/issue, especially through the web, to challenge established views on the issue.

This open source movement has also gained momentum in the area of cultural, food and beverage production and consumption. For example, the instructions for making home brew drinks such as OpenCola and LinuxCider are freely available, modifiable and can be redistributed as long as the terms and conditions of the GNU General Public License (GPL), the open source licence under which the original recipes were released, are met. With the emergence of Web 2.0 and other social media technologies, users (or audience) is invited to (re-)mix, (re-)distribute, (re-)generate new content. Further more, open source philosophies and practices have also been found in manufacturing, architecture and design, and this can be illuminated by the OScar project that has started applying open source principles into car development since 1999 (http://www.theoscarproject.org/), WikiHouse, an open source construction set that allows anyone to design, download, and 'print' CNC-milled houses and components, which can be assembled with minimal formal skill or training (http://www.wikihouse.cc/) (the Hexayurt Project, http://hexayurt.com/ is another libre housing project). Recently, hack spaces around the world (creative, independent co-working laboratories in cities) observe a even broader trend of "making" . These can be broadly linked with amateurism, Do-It-Yourself (DIY) culture, grassroots artisan activism, prosumption (Tapscott and Williams 2006) or produsage (Bruns 2008).

The trend of utilising, customising, localising, situating, domesticating, re-appropriating, repurposing, re-using, recycling, re-mixing the technologies in users' local contexts not only emphasises diverse consumers needs but also (implicitly) reflects a resistance to be controlled by big companies (a stereotypical and presumed roles and activities envisioned, designed and devised by developers and manufacturers). It can be a form of performance to challenge the intentions of producers and express resistance to dominant structures and values (e.g., Bilton et al. 1996 illustrate how youth subcultures, for example, have appropriated everything from the motor scooter to the safety pin to establish oppositional identities).

Participants in open source projects, too, demonstrate such 'a growing interest in novelty - a willingness to reject existing goods and practices in favour of new ones' (ibid. p. 35, Campbell 1992). In this regard, open source can be considered as a lifestyle, elected and subscribed by some. Consumption is no longer simply a passive activity; it could be a personal statement, a liberating, creative and varied experience. 
As found in other consumer goods, open source products are cultural, socio-technically constructed, mediating relationships and embodying meaning (Lin 2005). Open source goods can be associated with a range of social activities, and symbolises a desire of modern consumers for greater independence and individual everyday practices. For example, the recent growth of hacking events or maker fairs that celebrate open source practices and DIY mindsets in the areas of arts, crafts, engineering and (citizen) science fosters a culture in which building things and taking things apart tinkering, experimenting, and hacking - are encouraged. These events are usually associated with ideologies of sustainable living and ethical consumption. Moreover, open source can be considered as a paradigm shift in consumption that blurs the boundary between producers and consumers, between professional experts and amateurism / hobbyists, that ultimately leads to a shift in consumer attitudes and behaviours which may result in institutional and societal changes.

SEE ALSO: prosumption, produsage, crowd-sourcing, amateurism, DIY culture, grassroots artisan activism, reuse, recycle, hacking, tinkering,

\section{References}

Bilton, T., Bonnett, K., Jones, P., Skinner, D., Stanworth, M. and Webster, A. 1996. Introductory Sociology. $3^{\text {rd }}$ edition. London: Macmillan.

Bruns, A., 2008. Blogs, Wikipedia, Second Life, and Beyond: From Production to Produsage. New York: Peter Lang.

Campbell, C. 1992. "The desire for the new". In R. Silverstone and E. Hirsch (eds), Consuming Technologies, London, Routledge.

Coleman, G. 2013. Coding Freedom: The Ethics and Aesthetics of Hacking. Princeton University Press.

DiBona, C., Ockman, S. and Stone, M. (eds.) 1999. Open Sources: Voices from the Open Source Revolution. Sebastopol, CA: O'Reilly.

Huysman, M. and Lin, Y.-W. 2005. "Learn to solve problems: a virtual ethnographic case study of learning in a GNU/Linux Users Group". Electronic Journal for Virtual Organizations and Networks, 7. URL: http://hdl.handle.net/1871/15850 (Retrieved on 7 April 2013).

Lin, Y.-W. 2005. Hacking Practices and Software Development: A Social Worlds Analysis of ICT Innovation and the Role of Open Source Software. Unpublished PhD Thesis, Department of Sociology, University of York, UK.

Lin, Y.-W. 2011. “A Qualitative Enquiry Into OpenStreetMap Making”. New Review of Hypermedia and Multimedia, 17(1): 53-71.

Moody, G. 2002. Rebel Code: Linux and the Open Source Revolution. New York: Basic Books.

Raymond, E. S. 2001. The Cathedral and the Bazaar. Sebastopol, CA: O'Reilly.

Torvalds, L. and Diamond, D. 2011. Just for fun: The story of an accidental revolutionary. New York: HarperCollin.

Tapscott, D. \& Williams, A., 2006. Wikinomics: How Mass Collaboration Changes Everything. New York: Portfolio. 